\title{
The self-reported human health effects associated with heat exposure in Agincourt sub-district of South Africa
}

\author{
Albert Edgar Manyuchi (i) ${ }^{1 凶}$, Coleen Vogel ${ }^{1}$, Caradee Y. Wright ${ }^{2,3}$ \& Barend Erasmus ${ }^{4}$
}

Exposure to heat and heatwaves are associated with mortality and may amplify morbidities. In a climate change context, projections suggest temperatures will likely rise in the foreseeable future. Our paper assesses the current knowledge on human health effects of heat exposure and gathered local knowledge of heat-health effects in a rural area of the Agincourt sub-district of South Africa. Existing, peer-reviewed published literature on heat effects on human health as well as heat-health indicators was reviewed. Interviews and structured observations to collect data on heat effects on human health in Agincourt sub-district were conducted. The Lancet Countdown heat-related indicators were applied as a framework against which to discuss our findings. A total of 93 participants who lived in Agincourt subdistrict for 5 years and more were interviewed. Participants reported that temperatures, especially summertime temperatures, had been rising over the past years. Health effects of heat were deemed more apparent in relation to morbidity. Heatwaves were not easily comprehensible as singular 'events', and their effects were poorly understood. The population groups disproportionately affected by heat included infants, the elderly, those living with disability and outdoor workers. High ambient temperatures were deemed to be associated with reduced labour productivity of outdoor workers. Community-level perceptions of heat impacts on health were mainly related to illnesses and diseases, with no understanding of mortality risk. Future health awareness campaigns that encompass the full range of heathealth impacts are essential to reduce vulnerability, morbidity, and mortality. Our study provided location-specific, qualitative, and indicator-aligned data for a geographic area expected to undergo significant heat stress in the future. The study findings have significant research, policy, and practice implications in similar resource-limited settings.

\footnotetext{
${ }^{1}$ Global Change Institute, University of the Witwatersrand, Johannesburg, South Africa. ${ }^{2}$ Environmental and Health Research Unit, South African Medical Research Council, Pretoria, South Africa. ${ }^{3}$ Department of Geography, Geoinformatics and Meteorology, University of Pretoria, Pretoria, South Africa. ${ }^{4}$ Faculty of Natural and Agricultural Sciences, University of Pretoria, Pretoria, South Africa. ${ }^{凶}$ email: albertedgar.manyuchi@gmail.com
} 


\section{Introduction}

he global average surface temperature is rising (Costello et al., 2009). The Intergovernmental Panel on Climate Change (IPCC) 2014 report states that the evidence of global warming due to human actions is unequivocal (IPCC, 2014). The 5 hottest years on record have occurred since 2015 (Watts et al., 2020a). Rising global temperatures, directly and indirectly, impact human health. Directly, heat can cause excess mortality and morbidity especially among vulnerable individuals such as children, persons with chronic illnesses, outdoor workers and the elderly (Gasparrini et al., 2017). Exacerbated by the heat island effect, persons living in urban areas are disproportionately affected by exposure to heat compared to those living in rural areas (Wichmann, 2017; Nana et al., 2019). Indirectly, hot conditions impact the spread and transmission rates of vector-borne and water-borne diseases as well as nutrition (Niang et al., 2014).

Global research on the health effects of heat is increasing. Among others, the 2015 Lancet Commission on Health and Climate Change developed and progressively monitors key heathealth indicators including vulnerability to the heat-related risks of climate change, exposure to temperature change, exposure to heatwaves, changes in labour productivity and the economic costs of heat (Watts et al., 2015; The Lancet, 2017; Watts et al., 2017). The 2020 report of the Lancet Countdown on health and climate change examines several dimensions of the effects of heat and heatwaves covering exposure, vulnerability, labour capacity and mortality resulting in a compendium of robust evidence for adaptation, planning and resilience for health (Watts et al., 2020a, 2020b). The Lancet Countdown reports present comprehensive findings on heat anomalies and human health, summarised in Table 1.

The findings show that global ambient temperatures are rising, and the frequency and intensity of heatwaves is increasing, adversely affecting labour productivity and human health worldwide.

Intrinsically, certain populations including children, outdoor workers, people older than 65 years, with chronic respiratory, cardiovascular, and diabetic diseases as well as those living in urban areas are more vulnerable to the health effects of heat than others (Watts et al., 2019). The heat vulnerability index includes indicators such as "proportion of the population over 65 years, the prevalence of cardiovascular, diabetes and chronic respiratory diseases among population over 65 years and the proportion of the population living in urban (i.e., urbanisation rate)", p. 11 (Cai et al., 2020). These indicators exclude persons that are vulnerable to heat due to limited access to healthcare, poor health status, low socioeconomic status, the prevalence of cooling devices or green areas in cities and the existence of heat early-warning systems (Watts et al., 2020a, 2020b).

Extremes of heat do not lead to new vulnerabilities but rather amplify existing human health vulnerabilities on the African continent - a resource-limited continent already burdened with infectious and non-communicable diseases as well as the dual HIV-Coronavirus pandemics (Agyepong et al., 2017). Despite these challenges, the national adaptation plans of African countries such as Botswana, Chad, Ghana, Zimbabwe, among others, are less focused on heat and heatwaves (Woodruff and Regan, 2019). Several African cities have also not implemented heatfocused risk assessments. South Africa is among the few African countries involved in a health system climate change assessment, preparedness, and resilience reporting and the country also has a draft national heat-health plan (Watts et al., 2020b).

While global research on heat impacts on health is growing, few studies are specifically focused on Africa (Watts et al., 2018). Existing Africa-specific studies examine the impacts of heat anomalies on various health outcomes, including inter alia mortality and morbidity; birth weight, still and preterm births; ebolavirus disease; cholera; and diarrhoeal diseases (Kynast-Wolf et al., 2010; Trærup et al., 2011; Azongo et al., 2012; Diboulo et al., 2012; Scovronick and Armstrong, 2012a, 2012b; Ng et al., 2014; Ng et al., 2014; Amegah et al., 2016; Scovronick et al., 2018; Boeckmann et al., 2019; Chersich et al., 2020). In trying to offset the gap in existing literature, our study investigated the perceived human health effects of heat in Agincourt sub-district of South Africa. This paper summarises the study results.

\section{Conceptual framework}

Framing the study through human health and heat indicators. While there are many topics that can be studied under human health and heat, our study is framed around existing indicators on human health and heat. These indicators specifically informed data collection tools as well as the study approach. Key human health-heat indicators from the European Centre for Disease Prevention and Control (ECDC), United States of America Centres for Disease Control (US-CDC) Environmental Public Health Tracking, US Environmental Protection Agency (EPA), Public Health England, National Integrated Heat Health Information System (NIHHIS), the Global Heat Health Information Network and the World Health Organisation were searched. Existing literature on heat-health indicators from other countries also helped in framing our study (English et al., 2009; Cheng and Berry, 2013; Navi et al., 2017; Ebi et al., 2018). The human heathealth indicators from these institutions as well as the 2020 Lancet Countdown Report are shown in Table 2.

A special study providing information for indicators. Given that the thematic areas on the data collection tools were premised on a wide variety of existing indicators, our study is conceptualised as a special qualitative case study (Yin, 2012). A qualitative study generally applies several methodologies, including interviews, observations, case studies and literature review to collect information on a specific phenomenon, situation and or population (Escobar, 1985). Such an approach also demands effective implementation of research methods and competent analysis of data for it to be credible. Our detailed explanation of the study methodology demonstrates our fidelity to these aspects.

\section{Methods}

Study setting and population. The study was conducted in Agincourt, a sub-district under Bushbuckridge Municipality in Mpumalanga province of South Africa. Some of the areas covered under this study as well as Skukuza airport (blue tag with aeroplane, lower right corner of map) where the meteorological data was provided are shown in Fig. 1.

The study covered areas that fall under the Agincourt Health and Socio-Demographic Surveillance System (HDSS) of the Rural Public Health and Health Transitions Research Unit of the South African Medical Research Council (SAMRC) and the University of the Witwatersrand (MRC/Wits Agincourt Unit). Given the extensive track record of the HDSS and Wits Agincourt Unit, our study was able to build on this track record with trust relations in place to undertake such research. The study area and population has been extensively described elsewhere, which precludes a repeat of the same information in this article (Tollman et al., 2008; Byass et al., 2010; Kahn et al., 2012; dos Santos et al., 2019).

Data collection. Multiple methods of data collection were used. To get baseline data on the health effects of heat, existing peerreviewed published literature on heat, heatwaves, vulnerability to 
Table 1 Summary of key findings on heat-health and adaptation indicators from Lancet Countdown Reports.

\section{Indicators}

Vulnerability to the heat-related risks of climate change

Year

Summary of findings

Rising ambient temperatures place vulnerable populations at increased risks across all WHO regions.

Populations in Europe and the East Mediterranean are particularly at risk, with $42 \%$ and $43 \%$ of their populations older than 65 years vulnerable to heat exposure.

2019 Vulnerability to extremes of heat continues to rise among older populations in every region of the world, with the Western Pacific, South-East Asia and African regions all seeing an increase in vulnerability of more than $10 \%$ since 1990.

2020 Vulnerabilities to extreme heat continue to increase in every region of the world, led by populations in Europe, with the Western Pacific region, South-East Asia region, and the African region all seeing an increase of more than 10\% since 1990.

Health effects of temperature change

2017 Between 2000 and 2016, human exposure to warming was about 0,9 ${ }^{\circ} \mathrm{C}$, more than double the global area average temperature rise during the same period.

2018 In 2017, although the global mean temperature increase relative to the 1986-2005 reference period was $0.3^{\circ} \mathrm{C}$, the increase in human exposure temperature (the temperature increase in populated zones) was more than double at $0.8^{\circ} \mathrm{C}$.

2019 Human populations are concentrated in the areas most exposed to warming, experiencing a mean summer temperature change that is four times higher than the global average. Moreover, the global average

population-weighted temperature has risen by $0.8^{\circ} \mathrm{C}$ from the $1986-2005$ baseline to 2018 , compared with a global average temperature rise of $0.2^{\circ} \mathrm{C}$ over the course of the same period.

2020 Heat-related mortality in people older than 65 years increased by $53 \%$ and, in 2018, reached 296000 deaths, the majority of which occurred in Japan, Eastern China, northern India, and Central Europe.

Health effects of heatwaves/ exposure of vulnerable populations to heatwaves

2017 Between 2000 and 2016, the number of vulnerable people exposed to heatwave events increased by about 125 million, with a record 175 million more people exposed to heatwaves in 2015.

2018 An additional 157 million (an increase of 18 million additional exposure events compared with 2016) people were exposed to heatwaves events in 2017 compared with 2000, and with the average person experiencing an additional 1.4 days of heatwaves per year over the same period.

2019 In 2018, an increase of 220 million heatwaves exposure affecting older populations was observed, breaking the previous record set in 2015. Japan alone experienced 32 million heatwave exposures, the equivalent of almost every person aged 65 years and older enduring effects of heatwaves in 2018.

2020475 million additional exposures to heatwaves affected vulnerable populations were observed in 2019, representing some 2,9 billion additional days of heatwaves experienced.

Change in labour capacity

2017 Global labour capacity in rural populations exposed to temperature change is estimated to have decreased by 5.3\% from 2000 to 2016

2018 In 2017, 153 billion hours of labour were lost, an increase of 62 billion hours lost relative to 2000 .

2019 In 2018, 45 billion additional potential work hours were lost due to rising temperatures, compared with in the year 2000.

2020 Rising temperatures were responsible for an excess of 100 billion potential work hours lost globally in 2019 compared with those lost in 2000, with India's agricultural sector among the worst affected.

Climate information services for health

2017 73\% of the 100 responding WHO member states reported providing climate information climate information to the health sector in their country.

2018 The national meteorological and hydrological services of 53 countries report providing climate services to the health sector.

2019 The number of countries providing climate services to the health sector increased from 55 in 2018 to 70 in 2019

2020 The number of countries reporting that their meteorological services are providing climate services for health increased from 70 to 86 months during the past 12 months.

Source: Lancet Countdown reports 2017, 2018, 2019 and 2020.

heat exposure and risks associated with heat events was comprehensively reviewed. Searches using 'advanced search' option were done on PubMed, Scopus and Science Direct applying the following phrases: Health effects of heat in Africa; Heat events and health in Africa; Vulnerability to heat in Africa; Vulnerability to heatwaves in Africa; Extreme heat events and human mortality in Africa; Extreme heat events and human morbidity in Africa;
Heatwaves/ heatwaves and human mortality in Africa; Heatwaves/heatwaves and human morbidity in Africa; High ambient temperatures and human mortality in Africa; and High ambient temperatures and human morbidity in Africa. A total of 3457 articles were screened, of which 3365 were excluded and 92 full texts were downloaded and reviewed. References of downloaded full-text articles were further checked, and relevant articles 


\section{Table 2 Summary of available/applied human-related heat-health indicators.}

\section{Indicators from various institutions or Indicator explanation}

organisations

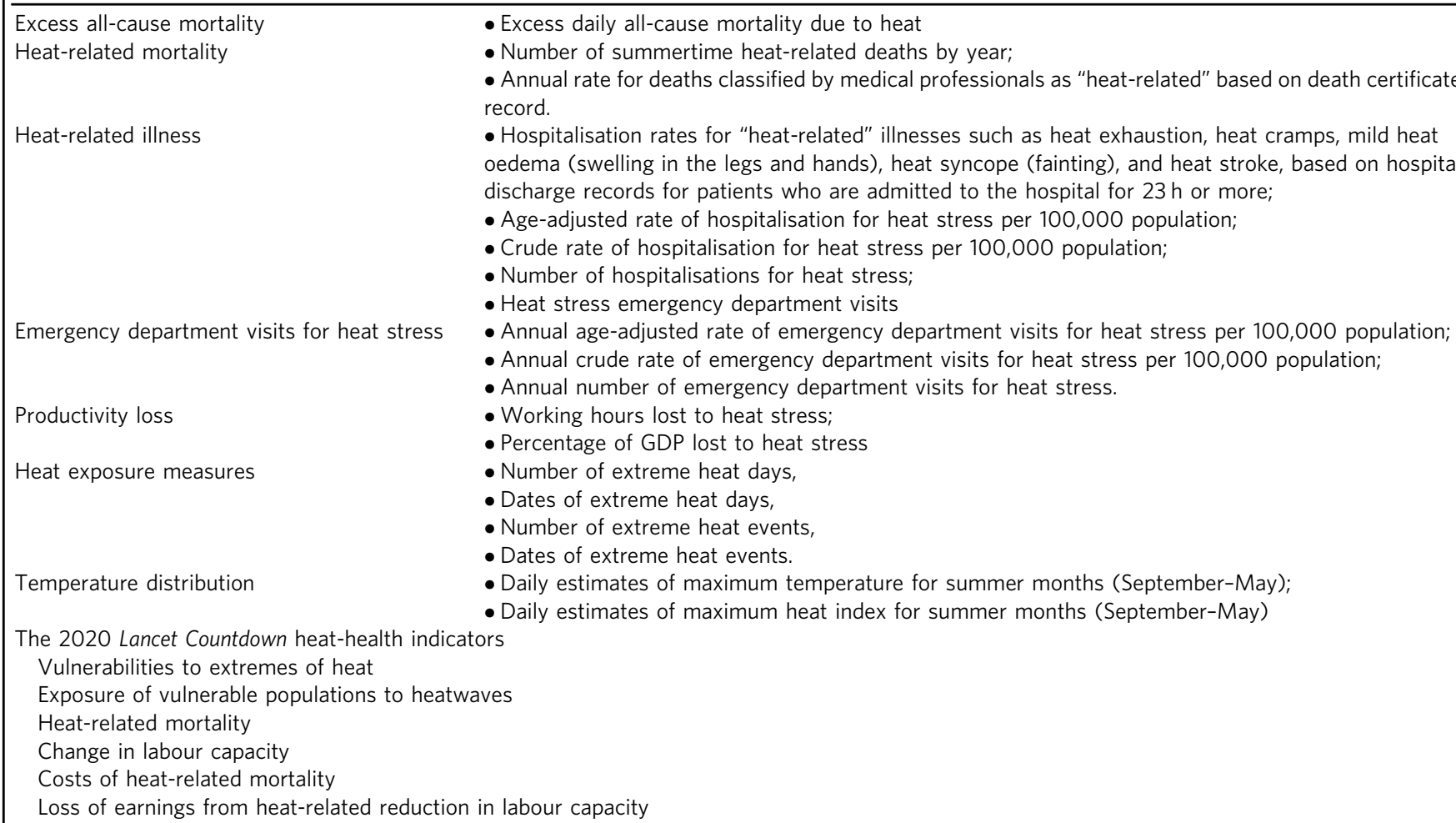

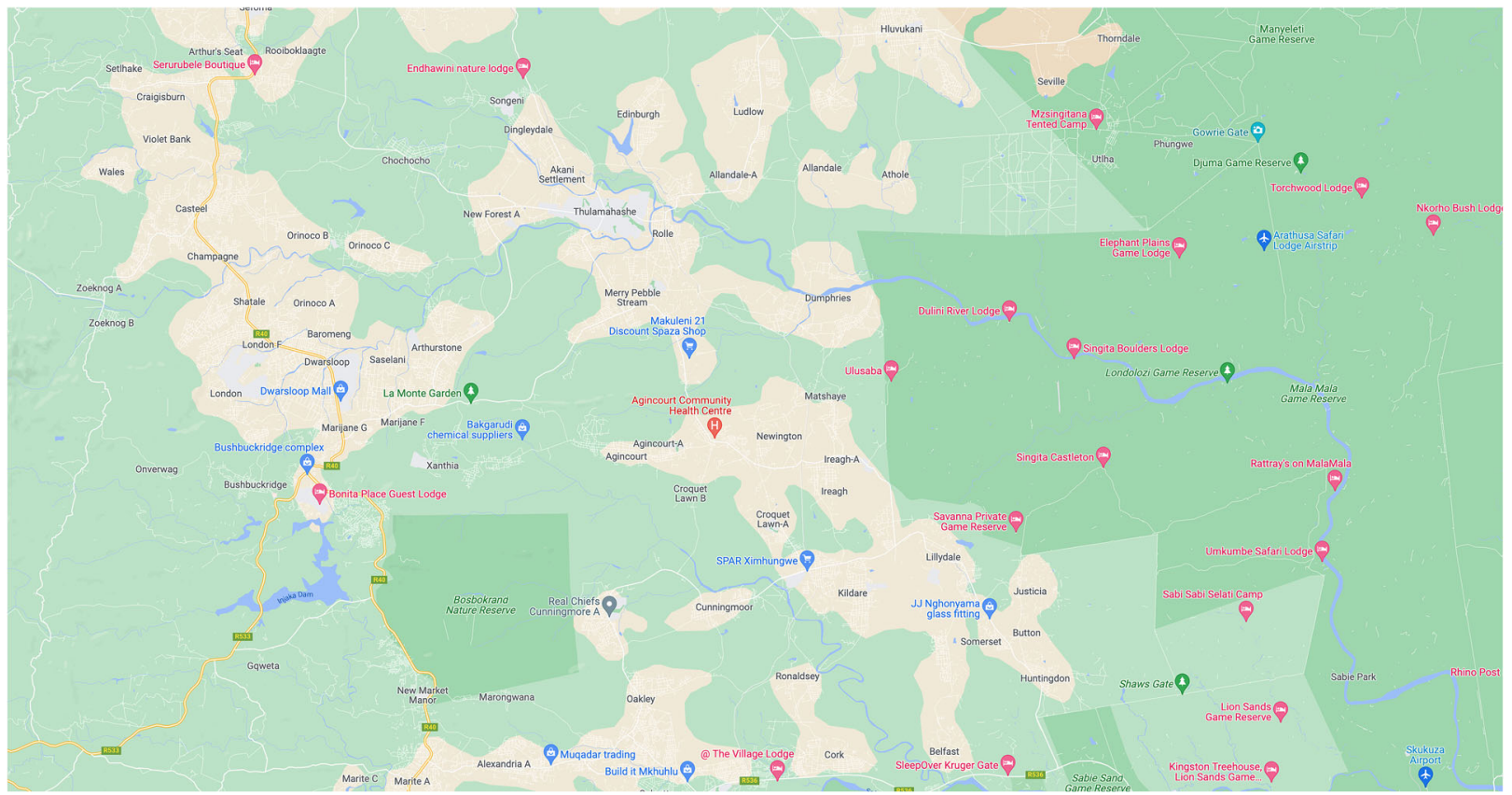

Fig. 1 Study area including Agincourt sub-district and Skukuza Airport. This figure is not copyrighted and reproduced with acknowledgement of Google Maps.

retrieved and reviewed resulting in exclusion of 49 articles and inclusion of 43 articles.

To understand the meteorological climatology of the area, meteorological data were provided by the South African Weather Service (SAWS). These data included temperature (minimum, maximum and average temperature) and humidity (minimum, maximum and average) variables and were analysed to describe diurnal seasonal trends. There is no official weather station located in Agincourt sub-district. Hence, the data from the nearest official weather station at Skukuza airport, which is 
located a few kilometres from Agincourt area were relied on. A previous study demonstrated minor temperature variations between the two sites and used the station's dataset as well (Byass et al., 2010).

Primary data were collected through interviews and structured observations. The data were collected between September and October 2019 and further updated in March 2020. These periods straddle the winter and summer seasons in the country and therefore enable some period of post event reflection as opposed to undertaking any interviews during the peak of a heatwave that may dramatically influence perceptions and results.

With the public relations support of the South African Medical Research Council /Wits Agincourt Unit staff, the primary author carried out in-depth, face to face interviews. One interview guide for key informants and another for community members were used to gather data during semi-structured interviews. Key informants, that is, knowledgeable and experienced persons, including teachers, health workers, personnel from meteorological stations, Kruger National Park and research institutions were identified and interviewed. Targeted interviews with recommended and non-referred community members, including inter alia traditional healers, faith healers, chiefs, outdoor workers, the aged, youths and the chronically sick were also carried out using the community interview guide. These interviewed community members are generally referred to as study respondents. Wherever the results from both key informants and respondents are reported, they are referred to as participants.

The interview guides covered several themes, including inter alia changes in ambient temperature over the past years, vulnerability to the heat-related risks of climate change, exposure to temperature change, definition of heatwaves, exposure to heatwaves, heat-focused interventions, population groups most vulnerable to heat, heat-related mortality, heat-related illness, hospitalisation due to heat, costs of heat-related mortality and loss of earnings from heat-related reduction in labour capacity.

Participants were permitted to explore the study topics in detail, and follow-up probing questions were used to elicit further information on any issue that needed detailed attention or verification. Interviews were mainly carried out in English, with an interpreter used to translate a few interviews from Shangaan to English. The interpreter was trained so that he became more familiar with the process and as well as when to probe for more information. Interviews lasted between 45 and $60 \mathrm{~min}$. All interviews were audiotaped using a handheld recording device, and notes were taken as well during the interviews.

Structured observations targeting schools, health facilities and other informal workplaces were also undertaken to try and ensure not only for additional data but also much needed verification and quality assurance. The personal and professional activities and interactions as well as heat interventions at the different venues during the times when it was deemed too hot were observed. For example, the activities, interactions, and responses to midday heat by outdoor workers involved in brickmaking, farming, carpentry and construction were observed at several venues. The structured observations lasted about $2 \mathrm{~h}$. Structured observation reports were generated showing the venue, date and time of observation, main activities, potential heat effects to the venue occupants, heat-related interventions, general health conditions, and the conditions of the general surroundings. Data saturation was reached when consistencies in data was achieved, and data related to specific themes became repetitive.

Data analysis. Secondary data from the reviewed literature were analysed against the key heat-health research themes, including heat-related mortality, heat-related illness, hospitalisation due to heat, vulnerability to heat, exposure of vulnerable populations to heatwaves and change in labour capacity. Theme-based summaries were written and reviewed.

Historical meteorological data from the SAWS were analysed. All gaps in the existing meteorological data were dealt with through communicating with officials from the SAWS. The historical meteorological data were analysed to validate qualitative findings from key informants and other study participants.

Primary interview data were analysed using a thematic approach. Data analysis followed an adapted six steps process similar to that outlined by Braun and Clarke (2006). The recorded audiotaped data were transcribed verbatim using Atlas $\mathrm{Ti}$ software package. Transcribed data were read and reread to ensure that details were being understood and captured. Repeating patterns in the data were identified and analysed, followed by sorting and the creation of codes, that is, the assignment of labels to words or phrases that represented recuring themes in each interview. Themes were then generated from these codes. The identified themes were then refined and assessed. Summaries of findings were written under each theme.

All data sources were triangulated. Thus, theme-based summaries from secondary and primary data sets were collated and converged first and consequently analysed together with the meteorological data sets. Triangulation of the data sources helped in enhancing the rigour of the research, especially trustworthiness of research findings. Through triangulation of data sources, a comprehensive understanding of the perceived heat effects on health in Agincourt sub-district was provided. Summaries of findings were written under each theme.

Data presentation and reporting. Although a variety of heathealth indicators from various institutions were reviewed (English et al., 2009; Cheng and Berry, 2013; Navi et al., 2017; Ebi et al., 2018) and could have used these indicators to report the data contained in the integrated theme-based summaries, reporting our findings guided by the indicators contained in the 2020 Lancet Countdown report was considered more appropriate. The reasons for this choice include that the 2020 Lancet Countdown indicators are consolidated and easily accessible; internationally recognised; overlap with those from other institutions; resulted from regular reviews done since 2015 and are the most updated. Therefore, only the theme-based summaries that could respond to the 2020 Lancet Countdown heat indicators were selected and the findings are presented here.

\section{Key findings on human health and heat in Agincourt sub- district}

In this section, the demographic composition of the participants, followed by the findings under the eight broad themes identified using thematic analysis are presented.

Demographic and socioeconomic characteristics of study participants. Of the 93 study participants, $69 \%$ were South African citizens (21\% were from Mozambique) and $54 \%$ were males (Table 3). Available literature shows that such participation is not unusual given that a significant number of persons resident in the area are migrants from neighbouring African countries who came in search of employment in farms and mines (Collinson et al., 2014; Kabudula et al., 2017). Most participants (59\%) completed matriculation (12 years of primary and secondary school education), while $24 \%$ completed tertiary (colleges or university) education. About 29 and $33 \%$ of the Agincourt participants were employed in formal and informal sectors, respectively, and almost all respondents not residing in Agincourt were formally 
Table 3 Demographic and socioeconomic characteristics of participants.

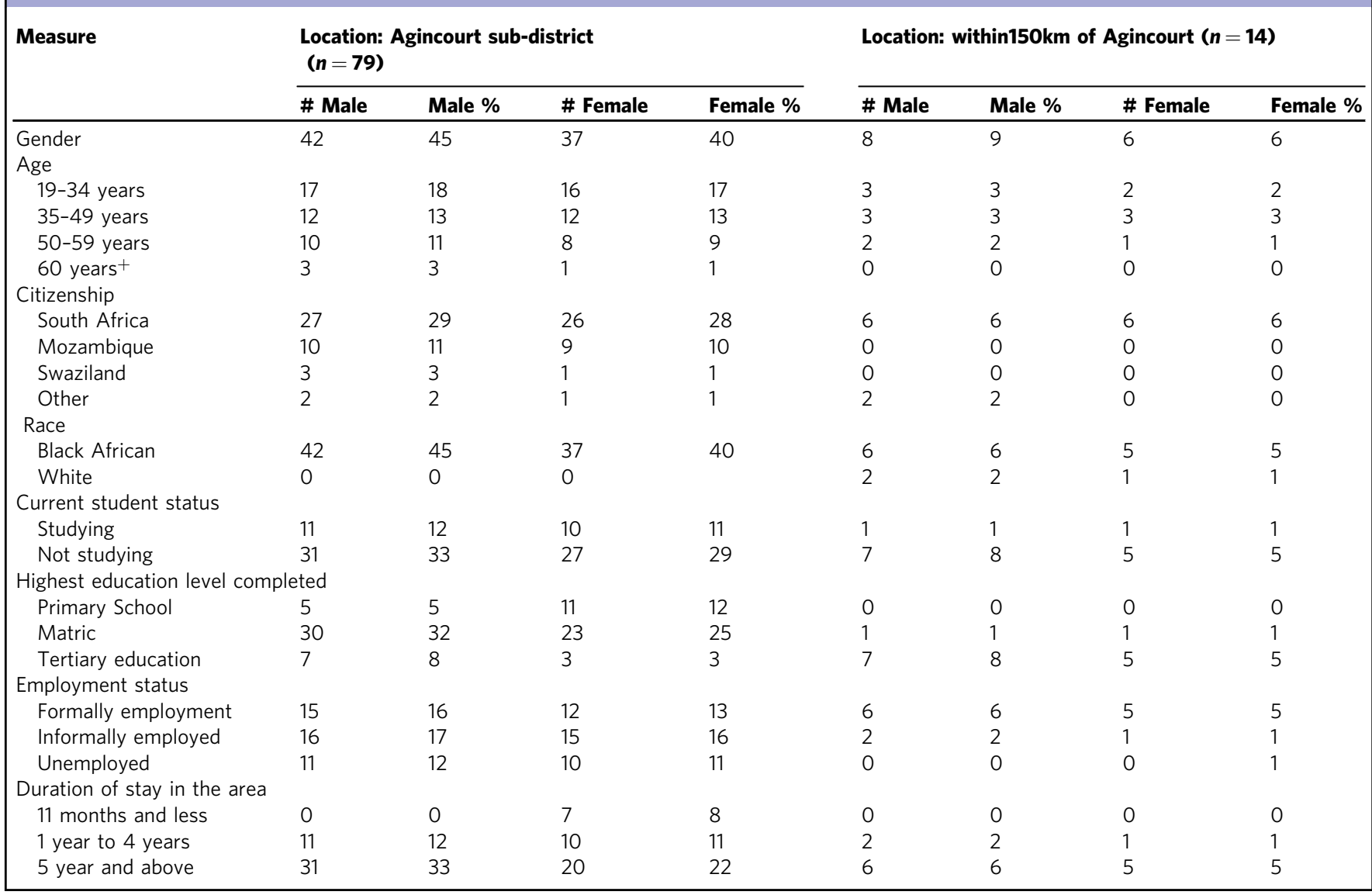

employed. Most participants (66\%) have lived for 5 years and more within 150 kilometres of the study area.

There were $38(41 \%)$ participants who were key informants with expert knowledge of the subject working in medical and educational facilities, airports, a meteorological station, national park and district and provincial offices as shown in Table 4. The other $55(59 \%)$ respondents were community members who could provide useful insights on the subject broadly categorised as shown in Table 4.

Climate background of Agincourt sub-district. Existing literature generally show that temperatures across South Africa are projected to increase at twice the global rate (Engelbrecht et al., 2015) and temperatures over the interior of regions the country are likely to increase by $2-3^{\circ} \mathrm{C}$ by 2050 and by $6-7^{\circ} \mathrm{C}$ by 2100 (Department of Environmental Affairs, 2011). However, few studies provide specific information about the climatic conditions of Agincourt sub-district. dos Santos et al. (2019: p. 4) state that "no other studies concerning changes in climate and health, or mortality indicators have been conducted in the Agincourt subdistrict yet".

Agincourt sub-district is located in the Lowveld Bushveld region characterised by moderate summer rainfall of between 500 to $700 \mathrm{~mm}$; warm to hot temperatures without any frost occurrences; high humidity, especially in summer; below average sunshine duration during summer for a savanna climate as well as marked increase in minimum temperature during the summer and autumn months between 1960 and 2001 (Kruger et al., 2002).

The Agincourt area is generally hot during the summer months -from September to April. Importantly, "since 1916, when regular observations began at Skukuza the temperatures have risen by about $0.05^{\circ} \mathrm{C}$ per decade" (Scholes et al., 2001: p. 75). In addition, the number of hot days and hot nights in the area have been increasing (Kruger and Shongwe, 2004). Much recent literature shows that while the maximum normal temperature at Skukuza between 1981 and 2010 was $30^{\circ} \mathrm{C}$, the highest average temperature recorded in 2018 was $32.6^{\circ} \mathrm{C}$ and the hottest daily temperature from 1981 to 2018 was $48.3^{\circ} \mathrm{C}$ recorded on 10 February 2012 (South African Weather Service, 2019). These data confirm that mean daily temperature in Agincourt sub-district rose by $1.5^{\circ} \mathrm{C}$ between 1992 and 2013 (Byass et al., 2017). This long-term data shows that temperatures in Agincourt area have been rising and will continue to rise in future unless drastic measure are taken to reduce global warming.

There is also evidence of increased weather events associated with climate change and variability around the area. The data from 1983 to 2012 shows that Skukuza weather station recorded 21 heatwave occurrences over this period (Mbokodo et al., 2020). Although not specific to Skukuza, on 27 May 2018, a severe hailstorm hit the lowveld area of Mpumalanga causing extensive damage in the area (South African Weather Service, 2019).

Existing literature indicates that climate change will impact the incidence and spread of vector-borne diseases, especially malaria (Byass et al., 2017). The 21-year Agincourt sub-district mortality data indicates relatively low mortality related to malaria, that is, about 180 deaths recorded in the area between 1992 and 2013 (Byass et al., 2017; dos Santos et al., 2019). Therefore, Agincourt sub-district is a low-transmission malaria area, notwithstanding the association between malaria mortality and temperature established in existing literature (Byass et al., 2017). 
Table 4 Summary characteristics of key informants and respondents.

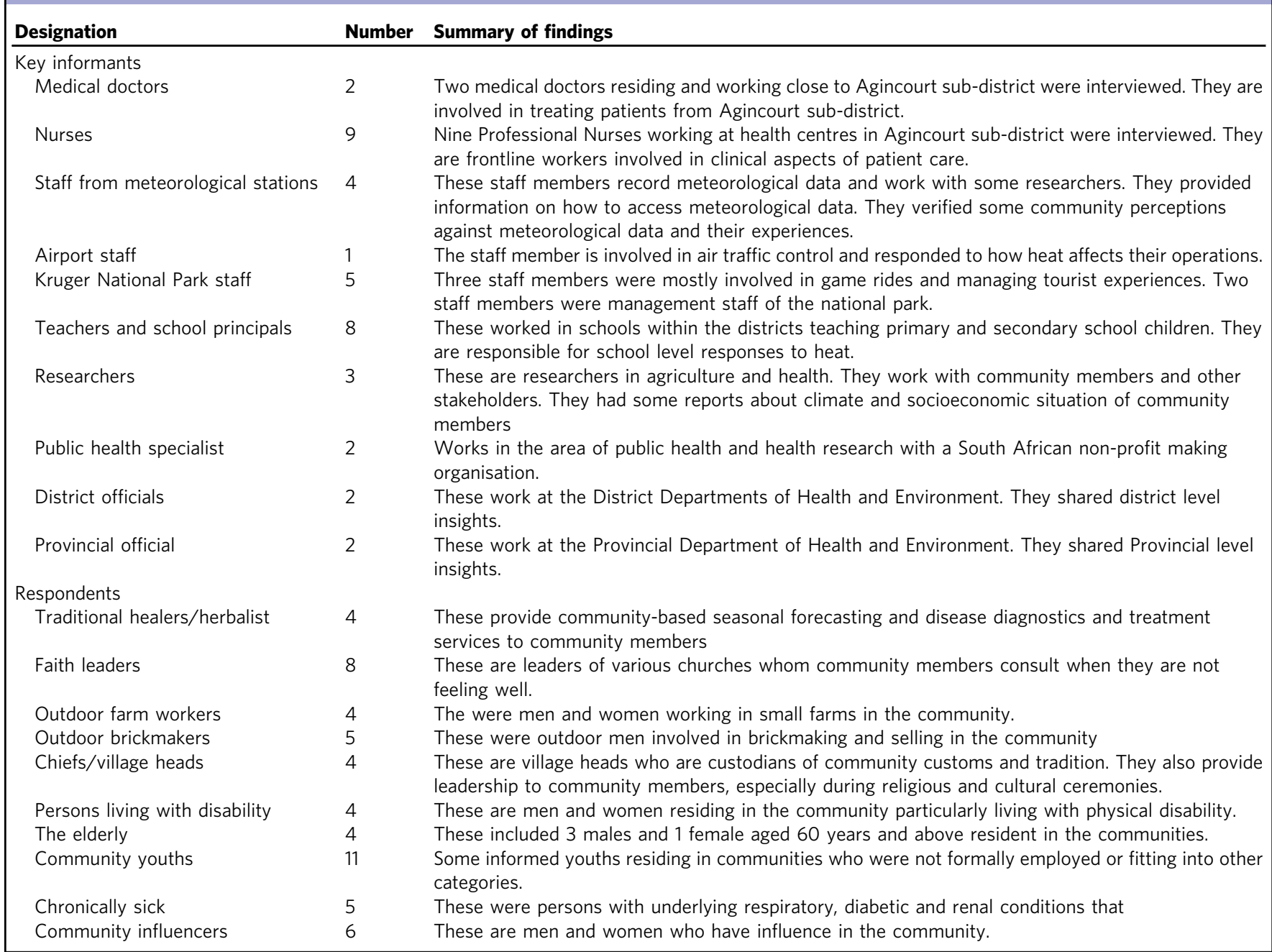

Perception of vulnerability to the heat-related risks of climate change. In this section, the findings from primary data are presented. Participants stated that the Agincourt area is generally a 'hot' place. The summer season stretches between September and April each year. Those who have lived in the area for 10 years and more stated that ambient temperatures are increasing, especially in summer. They noted that some water sources, such as wells, small natural pools and boreholes are drying out much earlier every year than before, albeit they refill during the rainy season. They also reported that there is now a significant amount of dust and wind as well as dry air. For the respondents, the early drying of water wells and boreholes, dusty winds and dry air demonstrate that temperatures are being perceived as being much hotter than they were in the past decade or so. Participants reported that temperatures are usually above $30^{\circ} \mathrm{C}$ and extremely hot days may go beyond $38^{\circ} \mathrm{C}$ during the summer months.

While the participants stated that the hottest months are October and November, the literature which reported meteorological data for the area suggests that January and February tend to be much hotter than these months (Kruger et al., 2002). A possible explanation for this difference may be that although January and February may be meteorologically hotter, the populations would have adapted to the heat over several months. In addition, January and February receive higher amounts of rain than October and November (Kruger et al., 2002), which can be associated with more cloud cover and may mediate the physical feeling of heat.

Since $66 \%$ of the participants have lived in or close to the area for 5 years and above, they highlighted that they have generally acclimatised to the high ambient temperatures experienced in the area. One respondent stated:

I arrived in Agincourt in August 2007. The temperatures were unbearable for me. Then in October and November 2007 , it became very hot and very uncomfortable. I could not sleep. I would force myself to go to work. But after that season, the body adapted. Right now, I only feel very hot days. Most of the time, I sleep and work without feeling the heat.

For both key informants and respondents, climate change appeared to be interpreted more readily as being linked to rainfall. They noted that they have not really reflected on increasing temperature changes in the area in relation to climate change and variability. One respondent explained:

We usually discuss climate change in relation to a good or bad rain season. We accept that temperature increases may be associated with climate change. But we have not investigated this much. Unlike rainfall which affects everyone, temperature changes are usually an individual affair. It is hot for a day or some hours. Therefore, we do 
not pay much attention to this. Since temperatures are on the increase, we are all vulnerable.

Some respondents stated that, while humans are vulnerable to heat associated with climate change, animals and infrastructures are also vulnerable. One respondent stated:

For me, there is a cycle of vulnerability. Heat will affect animals, water, plants, and infrastructure such as our shelter. This will in turn affect what humans eat, drink and where they stay. Human health is also affected. To adapt, humans will change the environment and the cycle repeats itself.

Overall, the various quotes show the different perspectives on vulnerability to heat, especially emphasising that the community is adversely affected by heat, albeit some people can acclimatise to high ambient temperatures over time.

Perception of exposure and vulnerability to extreme temperature change. Key informants demonstrated a clear understanding of the effects of exposure to heat, compared to study respondents. They highlighted that heat would cause vulnerability through reducing the availability of clean water sources for humans and animals and facilitate the spread of water-borne and vector-borne diseases. Both key informants and respondents, however, stated that it would be impossible for heat to cause deaths in the area. One respondent stated:

I don't think high temperatures will result in deaths here. Other people will intervene before the deaths happen. I think it is acceptable to say extreme temperatures can cause diseases.

Some respondents stated that heat affects many persons living in sub-standard dwellings in Agincourt area. A respondent noted that:

While we are affected by very high temperatures in one way or the other, I think the houses we live in differ. Bigger houses allow for air to circulate. Smaller houses make it difficult for air to circulate and are very hot to live in. Unfortunately, it is the poor such as the old people and orphaned children who are living in these sub-standard houses. They suffer more from very high temperature.

Similarly, key informants highlighted that vulnerability arose from lack of air conditioners in the villages. One key informant stated:

We suffer from hot conditions because we don't have air conditioners. If we had air conditioners, and electricity is uninterrupted, we would not be vulnerable to heat. We will just switch on the air conditioner and stay in cool places.

Another respondent stated that most villagers are vulnerable to heat because they must work to survive. The respondent noted:

We are vulnerable to hot weather because we have to go out there to work. We need money for us to survive daily. We mostly work in outdoor settings, especially farms and mines. Our working time is predetermined. It does not change because it is too hot. If you are lucky, you can take a break when it is too hot. We often work without rest to finish the work and get money. These circumstances make most villagers vulnerable to extreme temperature changes.

Some participants reported that vulnerability to heat could also differ based on individual physical characteristics. A respondent noted that persons who are overweight, taking chronic medication and with skin problems, such as albinos, suffer more from changes in temperature exposure, while a key informant suggested that nearly everyone in Agincourt area is vulnerable to temperature changes. He noted:

For me, vulnerability to temperature changes is both an environmental and personal matter. For instance, as soon as one feels hot and they regularly take water, they will not suffer much from the heat. However, without regular water intake, a person dehydrates. Persons most vulnerable to extreme heat are newcomers, old people, children, 'those disabled', the chronically ill and homeless. Also, everyone is vulnerable as extremely hot weather cause water bodies to dry up, and animals and humans to compete for fresh water.

Several participants included religion and beliefs in reflections in their responses to vulnerability to extreme temperature changes. These views are well represented by one respondent who commented:

vulnerability to extreme events, including heat and the effects there on people depend on God. I believe humans are as vulnerable as God wants. If God wants us to be sick from heat, then we will be. If God does not permit that, then nothing will happen.

Most of the quotes in this section emphasise that heat exposure mostly affects the poor and those who go out to work for local livelihood support. The conditions of housing, social capital and socioeconomic conditions are emphasised at factors that predispose persons to heat vulnerability.

Understanding, and perception of exposure and vulnerability to heatwaves. Existing South African regular weather updates allude to heatwaves without clearly defining a heatwave. Most participants did not understand the concept of a heatwave. Most argued that it was impossible for three or more consecutive hot days to occur. One key informant noted:

Here, temperatures soar during the day, and they lower at night. We have never experienced 3 consecutive extremely hot days and nights. I can give you several days when it was too hot, but the days were not consecutive. Maybe we would have adapted by the second day, or we would have found ways to protect ourselves from the heat. Given this, we do not feel the heat anymore after the first day. Meteorological data may prove whether I am right or wrong.

However, a key informant working in the education sector stated:

There are weeks when it becomes too hot. We stop lessons or change the venues where we deliver the lessons. Sometimes we allow children to go back home early...We may have experienced heatwaves during such weeks...but this is just my speculation. I cannot truthfully say there were three consecutive days that were extremely hot, even though I have been teaching here for 9 years.

As participants generally had a limited understanding of heatwaves/heat spells, it was impossible to explore, in detail, issues such as exposure and vulnerability to heatwaves, although much of what has been gathered could be included in such investigations in future. However, literature suggests that there are certain days when the area may be considered to have experienced heatwaves. 
Changes in labour productivity. Outdoor engagement in productive labour is a key factor that is usually impacted by increased periods of heat stress (Pogačar et al., 2018). In this study, most working people in the Agincourt area are engaged in outdoor, short-term informal employment. Both key informants and respondents pointed out that labour productivity reduces during extremely hot days. One respondent noted:

On a very hot day, the body is tired, even in the morning. There is nothing much that one can do when the body is already tired. Unless one works in air-conditioned environments, it is difficult to push the body to work in extremely hot weather...In general, people are present at work, but they achieve less.

\section{A key informant further pointed out that,}

Most people here work outdoors. When it is too hot, some good employers allow them to take longer breaks. Hence employees work in the morning and late in the afternoon. Despite this, they do not achieve the same results that they usually achieve when it is not too hot. Even teachers sometimes stop teaching and make children return home.

The times for effective teaching and learning are also impacted by heat stress. Just as noted in other cases (Puteh et al., 2012; Goodman et al., 2019) participants noted impacts on teaching and learning. A teacher highlighted that the decision to continue with lessons when it is very hot is not an easy decision to make. It depends on whether students remain attentive, if there is availability of water, possibility of students taking water-breaks and advice from the Department of Basic Education. The teacher further noted:

Lately, weather advice sometimes clearly state that teaching institutions must stop or change lessons times because it will be extremely hot. We use such weather advice to decide whether to suspend lessons or change the lessons delivery times.

Study participants also pointed out that labour productivity can be viewed as an individual rather than a community issue. One respondent stated that:

The issue of labour productivity is closely related to personal circumstances. While some people would like to work, even during extremely hot days, they have some medical conditions that make it impossible for them to work in hot weather...When we exclude these people, already the overall output is reduced. Some circumstances force people to work even if they should take a rest. There are many situations where you get paid only when the assigned task is completed. In these situations, productivity is not usually reduced.

Existing interventions focused on heat and human health. The existence of any current health interventions for heat in Agincourt area was explored in this study. Most participants stated that the most known intervention is drinking more water to avoid dehydration. In addition, community members sit in a shaded area, reduce outdoor work, minimise walking under direct sun, do not use blankets and may sleep outside of their dwellings during very hot evenings.

Although traditional healers highlighted that there are some traditional remedies for dealing with the effect of heat on people in the area, especially children, they were not willing to disclose the remedies. Further probing showed that traditional healers provided medication to deal with heat-induced diarrhoea. A few males stated that they take herbal concoctions that boost their immune system against many ailments, including heat-related illnesses. Some female participants disputed these claims stating that the herbs do not solve the effects of heat.

Exploring the role of interventions further, our study investigated how medical facilities in the area responded to periods of heat stress and related impacts. One doctor observed:

We generally provide oral rehydration solutions to patients that are dehydrated...at this stage, we do not have any community awareness programs focusing on the health effects of heat, even though campaigns are necessary.

Other clinical staff highlighted that clinicians treat the symptoms that the patient presents without carefully interrogating the origin and or 'driving factors' that may be giving rise to the patient's condition that would then exclude any further interrogation of any causal links between the effects of heat and the patient's symptoms. Except for cases of dehydration, diarrhoea and headaches, if a person visits a health facility with other illnesses, the medical staff prescribes the medication that cures the diagnosed sickness. Medical staff do not explore or investigate the social and environment conditions that may be leading to the illness unless the patient details these during initial contact. Time constraints for medical staff is a major barrier that limits detailed presentation of a patient's history.

\section{Discussion}

The subject of health and climate change in general and heat effects on human health is topical considering that the evidence of global warming is unequivocal, and many studies are showing that African countries are already experiencing increased temperatures over these past decades. Future projections are showing that the pattern of warming are not going to change, and adaptation and mitigation measures must be taken at all levels.

Qualitative data on self-reported heat effects on health in rural Agincourt sub-district from local participants were collected. These inputs were then compared to internationally evolving heat-health indicators, specifically those highlighted in the 2020 Lancet Countdown Report. With this investigation, facets of heat and health have been identified that may help to deepen and broaden the international evolution and use of indicators. Importantly, the empirical evidence reveals the effects of heat and heatwaves/spells on human health in Agincourt area.

Exiting literature show increased temperatures of about $0.05^{\circ} \mathrm{C}$ every decade from 1916 and an increase of $1.5^{\circ} \mathrm{C}$ between 1992 and 2013 specific to the Agincourt sub-district Kruger, (Makamo and Shongwe, 2002; Byass et al., 2017). These increases in temperature are significant and the responses provided in this study show that community members in Agincourt area were aware of changes in climatic conditions, especially changes in rainfall. Existing projections demonstrate that the area is amongst the places in South Africa that will experience increased heat in future unless current trajectories are consistently altered (Engelbrecht et al., 2015).

The impacts of the increased heat on human health were clearly articulated by the respondents and key informants, namely heat exposure has serious effects on morbidity. The community showed an understanding of heat effects on persons with underlying medical conditions and vulnerable populations groups such as the elderly and children. Despite this, current community actions to adapt to the effects of heat are simple, for example, drinking water and finding shade. There were no clear, sustained coordinated community responses to how to manage heat. This should be of concern because our study shows that some community members are vulnerable to heat exposure. 
In addition, when interpreting the results, there is need to consider the fact that exposure and vulnerability to heat has a strong relationship with economic outcomes (Lim and Skidmore, 2020). Heat will curtail the economic activities of many community members, especially those predominantly working in outdoor environments such as farms, open cast mines and in the informal sector activities, for example, street vendors. Increased heat weakens the economic base and in the absence of a clear intervention plan exposes populations to heat.

The current situation and future projections underscore the need for heat-health interventions and programs. Focused heat interventions are essential to reduce the risks associated with exposure to heat. It is important to provide essential heat-climate services for the region in order to achieve adaptation to heat and community resiliency. There is particular need to invest in heathealth interventions for the poor and most vulnerable. In addition, the confluence of factors associated with poor heat-health outcomes underscores the need for intersectoral actions.

Of concern is that the study showed community reliance on existing structures and social capital to mitigate mortality arising from heat and extreme heat events. However, this overdependence on community structures and systems is misplaced because studies from other settings show that extreme heat events disrupt community systems (Otto et al., 2012; Russo et al., 2015; Smith et al., 2016; Mbokodo et al., 2020). With projected increase in heatwaves and heat, deliberate efforts to strengthen the capabilities of community systems to respond to heat is essential.

In this study, evidence of community members coping with the changes in temperature was provided. Such information can inform researchers and policy makers. Our finding that community members reportedly gradually adapted to heat show that complex mechanisms and intricate factors, including biological, social, environmental and economic should be considered before attributing death and illness to heat and heatwaves (Vanos et al., 2020). In most settings, the detailed mechanisms for heat-health adaptation are not well established and our study did not detail these either-future studies should consider doing so.

Our finding on heatwaves provides new insights for heat-health response. Participants could not easily understand a definition of heatwaves, which is closely related to the internationally used definition. Participants failed to comprehend and agree to the fact that three consecutive, extremely hot days were required for a 'heatwave' to have occurred. The community did not recollect experiencing three consecutive days of extremely hot weather. The failure to define heatwaves/spells made it impossible for participants to provide explanations on the effects of heatwaves on human health, specifically vulnerability to heatwaves. This finding points to the need for more careful articulation of how concepts pertaining to heatwaves are being used both by scientists, policy makers but also by communities.

As stated before, our research of South African weather updates and existing literature showed that the term is loosely used without any consensus and elaborating the definition. Therefore, the role of language and meaning making is critical in such efforts and requires further research. Communities, health officials and policy makers need to understand the issues, and more critically offer inputs-for example, wording that may be in the vernacular but may better capture what the 'science' is trying to express. Despite this, our findings on the population groups most vulnerable to heat events, including inter alia children, the elderly and outdoor workers are similar to those found in existing literature (Azongo et al., 2012; Thompson et al., 2012; Amegah et al., 2016; Green et al., 2019).

Previous findings linked to heat periods and labour productivity, especially among outdoor workers, were corroborated in this research (Ngwenya et al., 2018). Indeed, the Agincourt sub-district is already experiencing periods of heat spells, and these are projected to increase in future. Such periods of heat stress, without any appropriate mitigating interventions, have the potential to negatively impact on outdoor workers, particularly those engaged in agriculture and indirectly on their dependents.

Future heat-health indicators monitoring. In this paper and research, the foundation for further research on understanding community-informed heat effects on health within African contexts has been provided. Evidence exists on the impacts of heat on health and effectiveness of interventions to potentially reduce heat-health stress impacts. While studies on heat and health in South Africa exist, some of them are not aligned to internationally recognised indicators, as undertaken in this study. The continued expansion and refinement of heat-health related indicators is a priority to many national and international agencies such as WHO, the Global Heat Information Network and the Lancet Commission on Health and Climate Change, among others. Specifically, studies on costs of heat-related mortality and loss of earnings from heat-related reduction in labour capacity in rural settings such as the Agincourt sub-district are imperative. Work is underway, albeit still unpublished, to define some key concepts such as heatwaves as well as to investigate the most relevant and applicable temperature variables for heat, particularly querying the use of minimum, maximum and average or diurnal temperature, the humidity measures, duration of sunshine and the role of metrices for wind speed and direction in the South African context. A key area of future work relates to translation of the draft South Africa heat policy into practice and examination of policy implementation against interventions and actual health outcomes.

In the present study, an innovative approach of gathering qualitative data and reporting it against the 2020 Lancet Countdown heat-health related indicators was applied. The qualitative method does not explicitly allow for any attributions to be made on heat effects on health. A more quantitative analysis of the same indicators using internationally recognised modelling approaches but focusing on the same area is currently under development as part of the heat effects on health in Agincourt sub-district study. In future work, our plan is to evaluate the quality of the studies focusing on heat and health in South Africa separated into quantitative and qualitative studies using a standardised approach so that an overall evidence summary is produced. Furthermore, our plan is to analyse gender and age as well as rural and urban dimensions in the existing evidence.

Strengths. There are some propositions underlying this special study. Our view is that there is a more fundamental philosophical question about the presentation of heat-health risk information. Should decision makers only pay attention to risk factor quantification for those heat-health risks supported by the strongest causal evidence? Or do notions such as the precautionary principle recommend that we should be mindful to risk quantification and explanations and even consider inconclusive evidence? Our argument is that response to heat-health risks that are considerably emerging risks in the African context can take considerable time and ignoring less definitive evidence may lead to worse health outcomes for society.

A number of strengths exist for our study. The triangulation of data sources enhanced the validity and reliability of the study results. Apart from this, the inclusion of 93 persons, of which $83 \%$ completed 12 years of primary and secondary as well as tertiary education, with equitable gender age participation, with 5 years and over in the area and inclusive of the diverse migrant and nonmigrant statuses, are core strengths of this study. 
Reporting our study findings against internationally evolving heat-health indicators is also innovative. The Lancet Countdown indicators are internationally renowned and evolving with a global monitoring framework in place. The yearly revisions and expansion of these indicators makes them dynamic and topical in the health and development agenda. Notably, continued improvement in indicator measurement is facilitated through studies that encompass them-and our study is one of these. A key issue is to ensure that the indicators are downscaled and tracked at national and sub-national levels. Our study contributes to the currently limited country-level and location-specific understanding that exposure to extreme heat is associated with serious health implications, especially in rural settings in Africa. This study thus provides invaluable empirical evidence for policy and practice, including enhancing the health of citizens moving given current and future climate stresses.

Limitations. The study presented here begins to trace some of the community-perceived links to periods of heat stress and its impacts. Study findings are based on self-reported responses and social desirability bias may have affected the participants responses. All attempts were made to avoid leading questions and short and clear questions were always used to minimise bias. Intrinsically, the study findings have limited generalisability. The study reported findings against the Lancet 2020 Countdown Report heat-health indicators and excludes other existing indicators reported in other reports. Whether the study findings would provide similar insights against the non-Lancet Countdown Report heat-health indicators has not been explored.

\section{Conclusion}

Understanding the effects of high ambient temperatures and heatwaves on human health is essential to assess risk, prioritise public health action and evaluate the success of different interventions and policies. This study provides a comprehensive assessment of eight heat-health indicators from a resource-limited African setting. Our findings show that community members believe that rising temperatures exacerbate the spread of diseases, i.e., morbidity, but have played a relatively unknown part in mortality. It is essential for public health actions to focus on the major heat-health risks in communities. Some of the risks are known by community members. Meteorological data as well as seasonal and short-term forecasts can compliment the local knowledge.

Our findings provide empirical evidence that reinforce the crucial need for robust monitoring of the risks to human health of heat. These findings support the need for raising awareness and creation of early-warning systems that strengthen community resilience to rising temperatures. These early-warning systems must be integrated into the healthcare system to ensure preparedness at primary healthcare facilities and clinics, especially in rural areas. Further location-specific research that informs the internationally evolving heat-health indictors, including those highlighted in the Lancet Countdown reports are encouraged.

\section{Data availability}

Qualitative data sets are restricted and not publicly available. Due to confidentiality agreements, supporting data can only be made available to bona fide researchers subject to a non-disclosure agreement. Details of the data and how to request access are available from A.E.Manyuchi at Global Change Institute of The University of the Witwatersrand.
Received: 17 August 2021; Accepted: 12 January 2022;

Published online: 11 February 2022

\section{References}

Agyepong IA et al. (2017) The path to longer and healthier lives for all Africans by 2030: the Lancet Commission on the future of health in sub-Saharan Africa. Lancet 390(10114):2803-2859. https://doi.org/10.1016/S0140-6736(17) 31509-X

Amegah AK, Rezza G, Jaakkola JJK (2016) Temperature-related morbidity and mortality in Sub-Saharan Africa: a systematic review of the empirical evidence. Environ Int 91:133-149. https://doi.org/10.1016/j.envint.2016.02.027

Azongo DK et al. (2012) A time series analysis of weather variability and all-cause mortality in the Kasena-Nankana districts of Northern Ghana, 1995-2010. Glob Health Action 5(SUPPL):14-22. https://doi.org/10.3402/gha.v5i0.19073

Boeckmann M et al. (2019) Climate change and control of diarrhoeal diseases in South Africa: Priorities for action. South African Med J 109(6):359-361. https://doi.org/10.7196/samj.2019.v109i6.14075

Braun V, Clarke V (2006) Using thematic analysis in psychology. Qual Res Psychol 3(2):77-101

Byass P et al. (2010) Assessing a population's exposure to heat and humidity: an empirical approach. Global Health Action 3(1):5421. https://doi.org/10.3402/ gha.v3i0.5421

Byass P et al. (2017) The long road to elimination: malaria mortality in a South African population cohort over 21 years. Global Health Epidemiol Genomics 2:e11. https://doi.org/10.1017/gheg.2017.7

Cai W, et al. (2020). The 2020 China report of the Lancet Countdown on health and climate change. Lancet Public Health 2020; published online Dec 2. https://doi.org/10.1016/S2468-2667(20)30256-5.

Cheng JJ, Berry P (2013) Development of key indicators to quantify the health impacts of climate change on Canadians. Int J Public Health 58(5):765-775. https://doi.org/10.1007/s00038-013-0499-5

Chersich MF et al. (2020) Associations between high temperatures in pregnancy and risk of preterm birth, low birth weight, and stillbirths: Systematic review and meta-analysis. BMJ 371:1-13. https://doi.org/10.1136/bmj.m3811

Collinson MA et al. (2014) Migration and the epidemiological transition: Insights from the Agincourt sub-district of northeast South Africa. Global Health Action, 7(SUPP.1). https://doi.org/10.3402/gha.v7.23514

Costello A et al. (2009) Managing the health effects of climate change. Lancet and University College London Institute for Global Health Commission. Lancet 373(9676):1693-1733. https://doi.org/10.1016/S0140-6736(09)60935-1

Department of Environmental Affairs (2011) National climate change response white paper. Government Publisher, Pretoria

Diboulo E et al. (2012) Weather and mortality: A 10 year retrospective analysis of the nouna health and demographic surveillance system, Burkina Faso. Glob Health Action 5(SUPPL):6-13. https://doi.org/10.3402/gha.v5i0.19078

dos Santos M et al. (2019) Climate change and healthcare sustainability in the agincourt sub-district, Kruger to Canyons Biosphere Region, South Africa, Sustainability (Switzerland), 11(2). https://doi.org/10.3390/su11020496

Ebi KL et al. (2018) Monitoring and evaluation indicators for climate changerelated health impacts, risks, adaptation, and resilience. Int J Environ Res Public Health 15(9):1-11. https://doi.org/10.3390/ijerph15091943

Engelbrecht F et al. (2015) Projections of rapidly rising surface temperatures over Africa under low mitigation. Environ Res Lett. IOP Publishing, 10(8). https:// doi.org/10.1088/1748-9326/10/8/085004

English PB et al. (2009) Environmental health indicators of climate change for the United States: Findings from the state environmental health indicator collaborative. Environ Health Perspect 117(11):1673-1681. https://doi.org/ 10.1289/ehp.0900708

Escobar WA (1985) An introduction to indicators. World Hosp 21(1):32-34

Gasparrini A et al. (2017) Projections of temperature-related excess mortality under climate change scenarios'. Lancet Planet Health 5196(Nov):360-367. https://doi.org/10.1016/S2542-5196(17)30156-0

Goodman J, Jisung MH, Smith PJ (2019) Heat and Learning, Working Paper 24639 http://www.nber.org/papers/w24639

Green $\mathrm{H}$ et al. (2019) Impact of heat on mortality and morbidity in low and middle income countries: A review of the epidemiological evidence and considerations for future research. Environ Res 171(Jan):80-91. https://doi.org/ 10.1016/j.envres.2019.01.010

IPCC (2014) Summary for Policymakers, Climate Change 2014: Synthesis Report. Contribution of Working Groups I, II and III to the Fifth Assessment Report of the Intergovernmental Panel on Climate Change. https://doi.org/10.1017/ CBO9781107415324

Kabudula CW et al. (2017) Progression of the epidemiological transition in a rural South African setting: findings from population surveillance in Agincourt, 1993-2013. BMC Public Health 17(1):1-15. https://doi.org/10.1186/s12889017-4312-x. BMC Public Health 
Kahn K et al. (2012) Profile: agincourt health and socio-demographic surveillance system. Int J Epidemiol 41(4):988-1001. https://doi.org/10.1093/ije/dys115

Kruger AC, Makamo LB, Shongwe S (2002) An analysis of Skukuza climate data. Koedoe 45(1):1-7. https://doi.org/10.4102/koedoe.v45i1.16

Kruger AC, Shongwe S (2004) Temperature trends in South Africa: 1960-2003. Int J Climatol 24(15):1929-1945. https://doi.org/10.1002/joc.1096

Kynast-Wolf G et al. (2010) Seasonal patterns of cardiovascular disease mortality of adults in Burkina Faso, West Africa. Trop Med Int Health 15(9):1082-1089. https://doi.org/10.1111/j.1365-3156.2010.02586.x

Lim J, Skidmore M (2020) Heat vulnerability and Heat Island Mitigation in the United States. Atmosphere 11(6), https://doi.org/10.3390/atmos11060558

Mbokodo I et al. (2020) Heatwaves in the future warmer climate of South Africa. Atmosphere 11(7):1-18. https://doi.org/10.3390/atmos11070712

Nana M, Coetzer, Vogel C (2019) Facing the heat: initial probing of the City of Johannesburg's heat-health planning. South African Geogr J 101(2):253-268. https://doi.org/10.1080/03736245.2019.1599412

Navi M et al. (2017) Developing health-related indicators of climate change: Australian stakeholder perspectives. Int J Environ Res Public Health, 14(5). https://doi.org/10.3390/ijerph14050552

Ng S, Basta NE, Cowling BJ (2014) Association between temperature, Humidity and ebolavirus disease outbreaks in Africa, 1976 to 2014. Eurosurveillance 19(35):1-11. https://doi.org/10.2807/1560-7917.es2014.19.35.20892

Ngwenya B et al. (2018) A review of heat stress policies in the context of climate change and its impacts on outdoor workers: Evidence from Zimbabwe. Int J Soc Ecol Sustain Dev 9(1):1-11. https://doi.org/10.4018/IJSESD.2018010101

Niang I et al. (2014) Africa, Climate Change 2014: impacts, adaptation and vulnerability-contributions of the working group II to the fifth assessment report of the intergovernmental panel on climate change. 1199-1265. Available at: https://ipcc-wg2.gov/AR5/images/uploads/WGIIAR5-Chap22_FINAL.pdf

Otto FEL et al. (2012) Reconciling two approaches to attribution of the 2010 Russian heat wave. Geophys Res Lett 39(4):1-5. https://doi.org/10.1029/2011GL050422

Pogačar T, Casanueva A, Kozjek K et al. (2018) The effect of hot days on occupational heat stress in the manufacturing industry: implications for workers' well-being and productivity. Int J Biometeorol 62:1251-1264. https://doi.org/ 10.1007/s00484-018-1530-6

Puteh M et al. (2012) Thermal comfort in classroom: constraints and issues. Procedia Soc Behav Sci 46:1834-1838. https://doi.org/10.1016/j.sbspro.2012.05.388

Russo S, Sillmann J, Fischer EM (2015) Top ten European heatwaves since 1950 and their occur- rence in the future. Environ Res Lett 10(12):124003. https:// doi.org/10.1088/1748-9326/10/12/124003. IOP Publishing

Scholes, RJ et al. (2001) The environment and vegetation of the flux measurement site near Skukuza, Kruger National Park, Koedoe 73-84. https://doi.org/ 10.4102/koedoe.v44i1.187

Scovronick N et al. (2018) The association between ambient temperature and mortality in South Africa: a time-series analysis. Environ Res 161(Nov):229-235. https:// doi.org/10.1016/j.envres.2017.11.001

Scovronick N, Armstrong B (2012a) The impact of housing type on temperaturerelated mortality in South Africa, 1996-2015. Environ Res [Internet]. 2012;113:46-51. Available from: https://doi.org/10.1016/j.envres.2012.01.004

Scovronick N, Armstrong B (2012b) Corrigendum to "The impact of housing type on temperature-related mortality in South Africa, 1996-2015" [Environ. Res. 113 (2012) 46-51]. Environ Res [Internet]. 2012;116:140. Available from: https://doi.org/10.1016/j.envres.2012.04.011

Smith S et al. (2016) Estimating the burden of heat illness in England during the 2013 summer heatwave using syndromic surveillance. J Epidemiol Commun Health 70(5):459-465. https://doi.org/10.1136/jech-2015-206079

South African Weather Service (2019) 'Annual Climate Summary for South Africa 2018', pp. 1-29. Available at: https://www.weathersa.co.za/Documents/ Corporate/AnnualClimateSummary2018FINAL.pdf

Trærup SL, Ortiz RA, Markandya A (2011) The costs of climate change: A study of cholera in Tanzania. Int J Environ Res Public Health 8(12):4386-4405. https://doi.org/10.3390/ijerph812438

The Lancet (2017) Counting down to climate change. The Lancet. Elsevier Ltd, 390(10107), 2016. https://doi.org/10.1016/S0140-6736(17)32809-X

Thompson AA, Matamale L, Kharidza SD (2012) Impact of climate change on children's health in Limpopo province, South Africa. Int J Environ Res Public Health 9(3):831-854. https://doi.org/10.3390/ijerph9030831

Tollman SM et al. (2008) Implications of mortality transition for primary health care in rural South Africa: a population-based surveillance study. Lancet 372(9642):893-901. https://doi.org/10.1016/S0140-6736(08)61399-9

Vanos JK et al. (2020) Simplicity lacks robustness when projecting heat-health outcomes in a changing climate. Nat Commun 11(1):10-14. https://doi.org/ 10.1038/s41467-020-19994-1. Springer US

Watts N, Adger WN, Agnolucci P et al. (2015) Health and climate change: policy responses to protect public health. Lancet, https://doi.org/10.1016/S01406736(15)60854-6
Watts $\mathrm{N}$ et al. (2017) The Lancet Countdown: tracking progress on health and climate change. Lancet 389(10074):1151-1164. https://doi.org/10.1016/ S0140-6736(16)32124-9

Watts $\mathrm{N}$ et al. (2018) The Lancet Countdown on health and climate change: from 25 years of inaction to a global transformation for public health. Lancet 391(10120):581-630. https://doi.org/10.1016/S0140-6736(17)32464-9

Watts, $\mathrm{N}$ et al. (2020a) The 2020 report of The Lancet Countdown on health and climate change: responding to converging crises. Lancet, 6736(20). https:// doi.org/10.1016/s0140-6736(20)32290-x

Watts N, Amann M, Arnell N, et al (2020b) The 2020 report of The Lancet Countdown on health and climate change: responding to converging crises. Lancet, (Supplementary appendix), https://doi.org/10.1016/S0140-6736(20)32290-X

Wichmann J (2017) Heat effects of ambient apparent temperature on all-cause mortality in Cape Town, Durban and Johannesburg, South Africa: 2006-2010. Sci Total Environ 587-588:266-272. https://doi.org/10.1016/ j.scitotenv.2017.02.135

Woodruff SC, Regan P (2019) Quality of national adaptation plans and opportunities for improvement. Mitig Adapt Strateg Glob Change 24:53-71. https:// doi.org/10.1007/s11027-018-9794-z

Yin RK (2012) Applications of Case study research (3rd Edition). Los Angeles/ London: Sage Publications Inc.

\section{Acknowledgements}

We would like to acknowledge the funding support for Albert Edgar Manyuchi from the Global Change Institute (GCI) of the University of the Witwatersrand. We would like to thank the MRC/Wits Agincourt Unit team, particularly Mr. Ngonidzashe Ngwarai, Dr. Rhian Twine, Prof. F. Xavier Gómez-Olivé and Dr. Chodziwadziwa Kabudula for their support.

\section{Competing interests}

The authors declare no competing interests.

\section{Ethical approval}

The study was approved by the Human Research Ethics Committee (Non-Medical) of the University of the Witwatersrand, Johannesburg, South Africa (proposal R14/49). This study further complied with the existing relevant ethics protocols for the Wits Agincourt Unit's surveillance and research work in the communities. Although the study was supported by the Global Change Institute (GCI) of the University of the Witwatersrand, the funding and technical partners of the GCI played no part in the study design, data collection, data analysis, data interpretation or writing of the article.

\section{Informed consent}

Written informed consent was obtained from all study participants. All participants provided written informed consent for recording and participating in the interview before the start of the interview. To ensure confidentiality, identifiers such as names of workplaces, health facilities and personal identifiers have been removed from the data presented in this study.

\section{Additional information}

Correspondence and requests for materials should be addressed to Albert Edgar Manyuchi.

Reprints and permission information is available at http://www.nature.com/reprints

Publisher's note Springer Nature remains neutral with regard to jurisdictional claims in published maps and institutional affiliations.

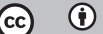

Open Access This article is licensed under a Creative Commons Attribution 4.0 International License, which permits use, sharing, adaptation, distribution and reproduction in any medium or format, as long as you give appropriate credit to the original author(s) and the source, provide a link to the Creative Commons license, and indicate if changes were made. The images or other third party material in this article are included in the article's Creative Commons license, unless indicated otherwise in a credit line to the material. If material is not included in the article's Creative Commons license and your intended use is not permitted by statutory regulation or exceeds the permitted use, you will need to obtain permission directly from the copyright holder. To view a copy of this license, visit http://creativecommons.org/ licenses/by/4.0/.

(c) The Author(s) 2022 